\title{
Article
}

\section{The Effects of Ultra-Low Viscosity Engine Oil on Mechanical Efficiency and Fuel Economy}

\author{
Yanyan Zhang ${ }^{1}{ }^{1}$, Ziyuan Ma $^{1}$, Yan Feng ${ }^{2}$, Ziyu Diao ${ }^{1}$ and Zhentao Liu ${ }^{1, *}$ \\ 1 Power Machinery \& Vehicular Engineering Institute, Zhejiang University, Hangzhou 310007, China; \\ 1061815381@zju.edu.cn (Y.Z.); 11527059@zju.edu.cn (Z.M.); diaoziyu2015@126.com (Z.D.) \\ 2 Zhejiang Engineering Research Center for Advanced Hydraulic Equipment, School of Mechanical and \\ Automotive Engineering, Zhejiang University of Water Resources and Electric Power, Hangzhou 310018, \\ China; fengy@zjweu.edu.cn \\ * Correspondence: liuzt@zju.edu.cn
}

check for updates

Citation: Zhang, Y.; Ma, Z.; Feng, Y.; Diao, Z.; Liu, Z. The Effects of Ultra-Low Viscosity Engine Oil on Mechanical Efficiency and Fuel Economy. Energies 2021, 14, 2320. https://doi.org/10.3390/en14082320

Academic Editor:

Francesco Castellani

Received: 17 March 2021

Accepted: 13 April 2021

Published: 20 April 2021

Publisher's Note: MDPI stays neutral with regard to jurisdictional claims in published maps and institutional affiliations.

Copyright: (c) 2021 by the authors. Licensee MDPI, Basel, Switzerland. This article is an open access article distributed under the terms and conditions of the Creative Commons Attribution (CC BY) license (https:/ / creativecommons.org/licenses/by/ $4.0 /)$.

\begin{abstract}
The development of a sustainable powertrain requires improved thermal efficiency. Reducing frictional power losses through the use of ultra-low viscosity oil is one of the most effective and economical ways. To assess the potential for efficiency enhancement in a new generation of future engines using low-viscosity oils, a technical analysis was conducted based on numerical simulation and theoretical analysis. This study proposes a numerical method coupling the whole multi-dynamics model and lubrication model under mixed lubrication regimes. Then, load distribution was calculated numerically and verified experimentally. Finally, this paper compares the bearing load and frictional energy loss of the main bearings when using The Society of Automotive Engineers (SAE) 15W40 and SAE 0W20 oil. The results indicate that the application of ultralow-viscosity lubricant can reduce the hydraulic friction loss up to $24 \%$, but the asperity friction loss would increase due to the reduction in load capacity. As a result, the design of a new generation of high efficiency internal combustion engines requires careful calculation and design to balance the trade-off relations between hydraulic friction and asperity friction.
\end{abstract}

Keywords: high efficiency engine; low viscosity oil; friction loss; fuel economy

\section{Introduction}

As the population increases the global demand for energy saving and emission reduction increases. The transport sector is one of the major consumers of energy and reducing fuel consumption of internal combustion engines (ICE) is the key to cut energy consumption and reduce $\mathrm{CO}_{2}$ emissions [1-5]. Holmberg and Erdemir [6] also reports that around $20 \%$ (103 EJ) of the world's total energy is used to overcome friction between moving parts. By taking advantage of the tribology design and method like lubrication technologies for friction reduction in vehicles, energy losses caused by friction can be reduced by $40 \%$ in the next 15 years and $1460 \mathrm{MtCO}_{2}$ emissions can also be reduced globally. Since most of the friction losses in the ICE occur at the cylinder inner surface with piston and piston ring mating and crankshaft bearing friction, the exploration of friction reduction for these sliding friction pairs is mainly in the areas of lubrication additives, application of advanced coating and surface technologies, precise lubrication theory and simulation techniques. Other works performed an overview of the combustion technologies that have been tested able to improve the $\mathrm{CO}_{2}$ and the NOx-Soot trade-offs such as specific bowl design, innovative fuel injection systems [7-10] and clean combustion technologies [11,12]. Studies have shown that reducing oil viscosity can be effective in improving fuel efficiency, but the problem that accompanies the application of lower viscosity oils is the accentuation of wear problems caused by the inadequate lubrication carrying capacity of lower viscosity oils [13]. The use of low viscosity lubricants in the automotive sector has been studied for a long time; however, increasingly stringent legislation is forcing the automotive industry to 
further improve the efficiency of engines, so lower viscosity lubricants are seen as the most economical way to achieve this goal [14].

The development trend of lubricants is a significant reduction in viscosity, the corresponding new standards are gradually been improved [15]. The Society of Automotive Engineers (SAE) also targeted to the viscosity standard of the SAE [16] for lower viscosity. With the increase in friction reduction requirements and the application of low viscosity lubricants, the fully dynamically lubricated state in the design will continue to decrease and gradually be replaced by a mixed lubricant state with a near minimum coefficient of friction [17]. Automotive multigrid lubricants are usually added with a variety of additives and the shear stress and shear strain rate are not linearly related to each other and show non-Newtonian characteristics. Although considerable progress has been made in EHL lubrication, it is still important to understand the rheological properties of the lubricant under EHL contact conditions [18].

In engineering practice, the correlation between the viscous-pressure effect and the non-Newtonian behavior of the oil causes these data to be difficult to measure and implement in the simulation due to the lack of the required rheological data for the oil. Existing simulation studies on low-viscosity oils in general-purpose tribological subsets generally use, for example, the Barus equation or Cross equation models alone to consider viscouspressure and shear thinning effects under isothermal conditions [19] and, although this is a reasonable approximation that is closer to real properties of the lubricant, the tribological behavior of the real integrated oil is more complex [17] and more difficult to measure. It was shown that the viscous compression effect needs to be taken into account when the local pressure approaches $200 \mathrm{MPa}$ and the shear thinning effect cannot be neglected when the shear rate reaches 1061 /s [20]. Bouzid et al. considered the combined effect of coupling stress and viscous compression effect on the dynamic characteristics of connecting rods in their study of connecting rod sliding bearings and found that the coupling stress and viscous compression effect have a significant effect on the nonlinear dynamic behavior of dynamically loaded bearings [21]. Parinam considered the shear thinning effect in the study of line contact sliding friction [22]. Meng and Xie et al. [23] considered both viscous compression and shear thinning effects of lubricants on the sliding friction subsets of internal combustion engines. Idemitsu [24] and Honda [13] conducted a series of meaningful explorations of the non-Newtonian properties of automotive oils. The interested reader is free to consult these works. There are also surface and material technics, since lubrication theory and simulation calculations allow the design check, modification and optimization in the design phase before the prototype comes out, the development cycle and economic cost are greatly reduced. Thus, it is preferred in several of the above studies.

Main lubrication states of lubricated friction pairs include hydrodynamic lubrication (HL), elastohydrodynamic lubrication (EHL), boundary lubrication (BL) and mixed lubrication (MHL). Research shows that the lubrication mode of each friction pair conforms to Stribeck curve under stable load and specified rotational speed, namely, the friction coefficient varies with the film thickness curve is the same as the curve below as shown in Figure 1. 


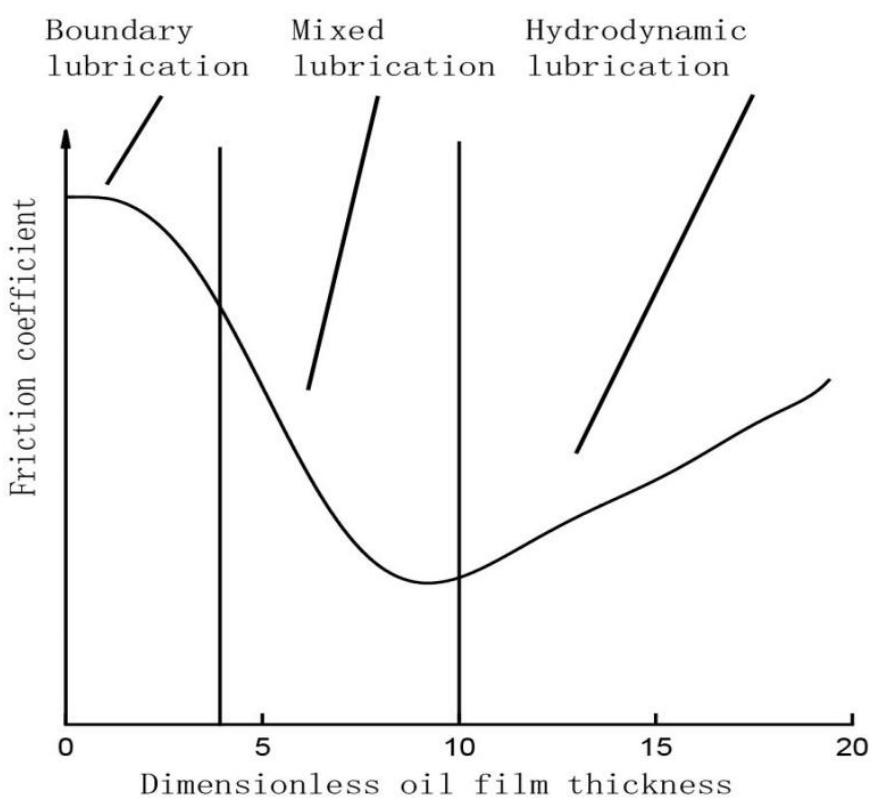

Figure 1. Stribeck curve.

The above Stribeck curve shows that the lubrication state gradually transits from boundary lubrication to hybrid lubrication and dynamic lubrication with the increase of dimensionless film thickness. As we known that multiple engine main crankshaft bearings usually support one crankshaft under the condition of being heated by the combustion chamber; therefore, the position and structure of bearings and bearing seats are strictly limited owing to the structure and working condition of the ICE. In addition, the flexibility of the main components of the internal combustion engine, such as crankshaft and engine block, should be considered under instantaneous high explosive pressure load working condition. Additionally, the difference of tribological properties between the bearings cannot be ignored considering the uneven stresses and the interaction force of them. Thus, a better design and analysis of bearings, including the lubrication and interaction between the friction surfaces of multiple bearings, are of critical importance.

The load capacity, friction loss and wear condition of the bearings are determined by the lubricant and the viscosity of which plays a leading role in the process of hydrodynamic lubrication. For the two surfaces of the friction pair separating by the lubricating oil film, the thickness of the oil film and the viscosity of the lubricating oil play a leading role in the friction loss and under the condition of mixed lubrication or even boundary lubrication, the nominal gap between the two surfaces is very small and the friction caused by the contact of rough peaks between the two sliding surfaces is more significant. The FEA simulation of internal combustion engine main bearing based on low viscosity oil needs to consider the following aspects:

1. as the internal combustion engine develops requiring higher explosion pressure and lighter weight, the influence of oil film local pressure on elastic deformation increases;

2. the viscosity-pressure effect and shear thinning effect on lubrication friction cannot be ignored for the local force of bearing oil film getting higher with high-speed shear force applying to extremely thin oil film;

3. mixed lubrication and even metal contact (side load) effect of main bearing exists caused by the dynamic load and complex working conditions of the internal combustion engine;

4. the influence of the surface quality and texture direction of the friction pair on the lubrication flow cannot be ignored for the oil film thickness and the roughness of the rough surface of the friction pair are being in the same order of magnitude; 
5. the distribution of lubricating oil film and the lubrication friction performance will be affected by which the main bearing will tilt in the main bearing for its own flexible deformation when the combustion pressure in cylinder breaking out;

6. the application of low viscosity oil will have a nonlinear effect on the combination of the above factors.

Therefore, a simulation method for the main bearings of ICE under the application scenario of low viscosity oil, with a multibody dynamicsmodel of crankshaft and multiple main bearings, considering the influence of asperity contact model and rough surface morphology characteristics must be established to evaluate the tribological characteristics of the ICE accurately. This work can be useful for the design of a new generation of high efficiency ICE and evaluation of the energy and economic benefits of the reduced friction losses from the use of ultra-low viscosity oil.

\section{Test Procedure}

This section aims to implement an engine bench test under properly selected working conditions. The data-such as the cylinder pressure, oil supply pressure and rotational speed, together with the ambient temperature in a large range of working conditionscomprising typical loads were collected and were used to gain the input boundary conditions of the simulation, since the accuracy of the kinetic model calculations strongly dependent on the dynamic boundary conditions.

\subsection{The Object Engine and Overall Arrangement}

For the experiment, a six-cylinder diesel engine is selected as the research object and its the main technical parameters are shown in Table 1.

Table 1. Engine characteristic parameters.

\begin{tabular}{ccc}
\hline Name & Unit & Value \\
\hline Bore diameter & $\mathrm{mm}$ & 116 \\
stroke & $\mathrm{mm}$ & 139 \\
Cylinder distance & $\mathrm{mm}$ & 144 \\
Design pressure & $\mathrm{MPa}$ & 20 \\
Rated speed & $\mathrm{r} / \mathrm{min}$ & 1900 \\
Rated power & $\mathrm{kW}$ & 247 \\
Maximum torque & $\mathrm{Nm}$ & 1600 \\
The speed at max. torque & $\mathrm{r} / \mathrm{min}$ & $1000-1400$ \\
Lubrication way & - & Pressure and splash \\
Oil type & - & $15 \mathrm{~W} 40$ \\
The diameter of the main & $\mathrm{mm}$ & 97.102 \\
bearing & $\mathrm{mm}$ & 97 \\
The diameter of the main shaft & - & $1-5-3-6-2-4$ \\
Fire order & &
\end{tabular}

The test bench and the overall arrangement of the equipment are shown as in Figure 2: 


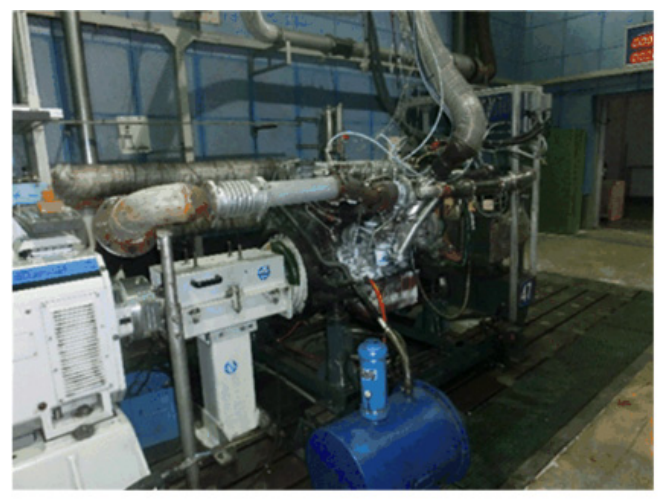

(a)

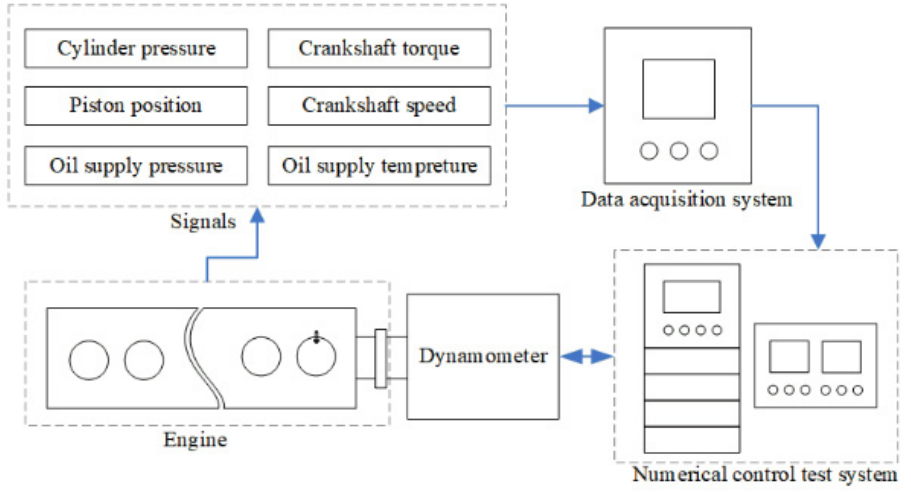

(b)

Figure 2. The arrangement of the experimental system: (a) test bench in the lab; (b) diagram of the experimental system.

A dynamometer is connected to the rear end of the engine; signals of the cylinder pressure, the piston top dead point position, the oil supply pressure, the rotational speed and torque of the crankshaft are transmitted to the data acquisition system, and the test bench are manipulated by a numerical control test system. The properties of the devices are shown in Table 2.

Table 2. Properties of the devices.

\begin{tabular}{cccc}
\hline Device & Sensor Model & Accuracy & Range \\
\hline $\begin{array}{c}\text { Fuel consumption } \\
\text { meter }\end{array}$ & AVL735 & $\pm 0.12 \%$ & $125 \mathrm{~kg} / \mathrm{h}$ \\
Dynamometer & JD 600 & Torque $\leq \pm 0.1 \% \mathrm{~F} . S$. & $3050 \mathrm{~N} \cdot \mathrm{m}$ \\
Combustion Analyzer & Kistler & Speed $\leq \pm 1 \mathrm{r} / \mathrm{min}$ & $0-3000 \mathrm{r} / \mathrm{min}$ \\
Cylinder pressure & $6052 \mathrm{C}$ & Nonlinearity $<0.3 \%$ & - \\
sensor & AVL735 & $\pm 1{ }^{\circ} \mathrm{C}$ & $0-250 \mathrm{bar}$ \\
Fuel thermostat & $5018 \mathrm{~A} 1000$ & - & - \\
Charge amplifier & $1603 \mathrm{C} 10$ & - & - \\
Cable & & & - \\
\hline
\end{tabular}

\subsection{Test Procedures and Operational Conditions}

The bench test was conducted under ambient circumstances and the selected typical operating conditions are shown in Table 3; the test procedure was also conducted accordingly. First, inject the fuel through the numerical control system to the combustion chamber to start the engine and drive the dynamometer, examine the output data of the engine speed, the torque and the temperature of the outlet of the engine cooling water; ensure that the data displayed are within the reasonable range and stable, then start the testing process.

Table 3. Test cycle conditions.

\begin{tabular}{ccc}
\hline NO. & Peak Pressure (MPa) & $\begin{array}{c}\text { The Rotational Speed } \\
(\mathbf{r} / \mathbf{m i n})\end{array}$ \\
\hline 1 & 25 & 1900 \\
2 & 25 & 1000 \\
3 & Engine calibration & 600 \\
4 & 25 & 1400 \\
5 & Engine calibration & 2150 \\
\hline
\end{tabular}

Adjust engine speed to the rated speed $(1900 \mathrm{r} / \mathrm{min})$, the combustion peak pressure to $25 \mathrm{MPa}$; record when the data are stabilized. In addition, the lower the engine speed 
to $1000 \mathrm{r} / \mathrm{min}$, the minimum speed on full load; record when the data are stabilized, too. Other subsequent working conditions are shown in the order in Table 3. The recorded combustion curve with the peak pressure of $25 \mathrm{MPa}$ and the engine calibration was drawn to curves.

\subsection{Results}

During the endurance test, the measured cylinder pressure curves are depicted in Figure 3. Other critical parameters, such as torque, power and oil supply, pressures are shown in Table 4.

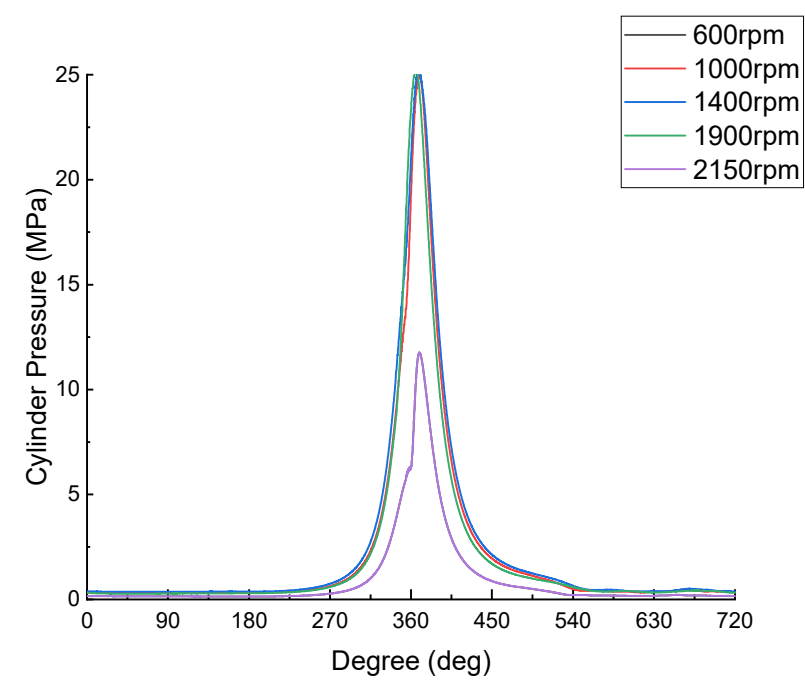

Figure 3. Measured cylinder pressure curve on each operating condition.

Table 4. Measured parameters under each operating condition.

\begin{tabular}{cccc}
\hline $\begin{array}{c}\text { The Rotational } \\
\text { Speed (r/min) }\end{array}$ & Torque (N. m) & Power (KW) & $\begin{array}{c}\text { Oil Supply Pressure } \\
\text { (MPa) }\end{array}$ \\
\hline 1900 & 0 & 0 & 216 \\
1000 & 1600 & 167.5 & 343.5 \\
600 & 1500 & 219.9 & 412.5 \\
1400 & 1241.5 & 247 & 419 \\
2150 & 0 & 0 & 419 \\
\hline
\end{tabular}

\section{Numerical Simulation Model}

\subsection{Governing Equations}

The dynamic equation of flexible multi-body considering both translation and rotation is described as follows:

$$
\begin{gathered}
M \cdot \ddot{q}+D \cdot \dot{q}+K \cdot q=f \\
f=f^{a}+f^{*}+p^{*}
\end{gathered}
$$

where the generalized coordinates are $q=\left(q_{1}, q_{2}, \cdots \cdots, q_{n}\right)^{\prime},\left(q_{i}=\left(u_{1}, u_{2}, u_{3}, \phi_{1}, \phi_{2}, \phi_{3}\right)_{i}^{\prime}\right)$; $f^{*}$ is the generalized force of the interaction between components; $f^{a}$ is the external load; $p^{*}$ is nonlinear inertial force and moment and its expression is as follows:

$$
p^{*}=f^{g}-f^{\prime}=\left(p_{1}^{*}, p_{2}^{*}, \cdots \cdots, p_{n}^{*}\right)^{t}
$$


where $f^{g}$ is the force and moment produced by the acceleration of the rigid body; $f^{\prime}$ is the centrifugal gyro force and moment.

$$
p_{i}^{*}=\left[\begin{array}{l}
-m_{i}\left[\ddot{x}_{B}+2 \cdot A_{\Omega} \cdot\left(\dot{x}_{B}+\dot{u}_{i}\right)+\left(A_{\Omega}+A_{\Omega}^{2}\right) \cdot\left(x_{B}+c_{i}+u_{i}\right)\right] \\
-\left\{\Delta I_{C_{i}} \cdot \ddot{\varphi}_{i}+\left(I_{C_{i}}+\Delta I_{C_{i}}\right) \cdot\left(\Omega-A_{q} \cdot \Omega\right)+\left(A_{\Omega}+A_{\varphi}\right) \cdot\left(I_{C_{i}}+\Delta I_{C_{i}}\right) \cdot\left(\Omega+\dot{\varphi}_{i}\right)\right\}
\end{array}\right]
$$

In the process of modeling, due to the complexity of the actual structure of cylinder liner piston connecting rod crankshaft and engine block, if each node is calculated after the finite element meshing, it is required to establish a huge equation group, which will lead to a huge amount of calculation. So, to simplify the equations, it is necessary to reduce the degrees of freedom of some nodes which have little influence on the calculation results. The commonly used CMS method and the substructure mode synthesis method are used to reduce the model. The transformation involved in the reduction process is as follows:

$$
q=\left[\begin{array}{l}
q_{t} \\
q_{0}
\end{array}\right]=\underbrace{\left[\begin{array}{cc}
E & 0 \\
G_{o t} & G_{o q}
\end{array}\right]}_{G_{f a}} \cdot\left[\begin{array}{c}
q_{t} \\
z
\end{array}\right]=G_{f a} \cdot q_{a}
$$

where $q$ is the reduced front node DOF vector; $q_{a}$ is the reduced degree of freedom; $G_{f a}$ is the transformation matrix. By substituting (5) into (1), the reduced form of the kinetic equation is

$$
\underbrace{\left(G_{f a}^{\prime} \cdot M \cdot G_{f a}\right)}_{\bar{M}} \cdot \ddot{q}_{a}+\underbrace{\left(G_{f a}^{\prime} \cdot D \cdot G_{f a}\right)}_{\bar{D}} \cdot \dot{q}_{a}+\underbrace{\left(G_{f a}^{\prime} \cdot K \cdot G_{j a}\right)}_{\bar{K}} \cdot q_{a}=\underbrace{G_{f a}^{\prime} \cdot f}_{\bar{f}}
$$

The above formula can be simplified as

$$
\bar{M} \cdot \ddot{q}_{a}+\vec{D} \cdot \dot{q}_{a}+\bar{K} \cdot q_{a}=\bar{f}
$$

Simplify the Navier-Stokes equations in the direction of oil film thickness; the Reynolds equation is used in the circumferential and axial direction of the bearing:

$$
\frac{\partial}{\partial x}\left(\frac{h^{3}}{12 \cdot \eta} \cdot \frac{\partial p}{\partial x}\right)+\frac{\partial}{\partial z}\left(\frac{h^{3}}{12 \cdot \eta} \cdot \frac{\partial p}{\partial z}\right)=\frac{U_{1}+U_{2}}{2} \cdot \frac{\partial h}{\partial x}+\frac{\partial h}{\partial t}
$$

The lubricating oil film expands along the circumference from the vertex of the bearing into a long square area, as shown in Figure 4:

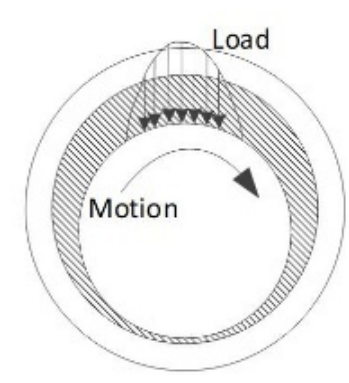

(a) Loading diagram of single bearing

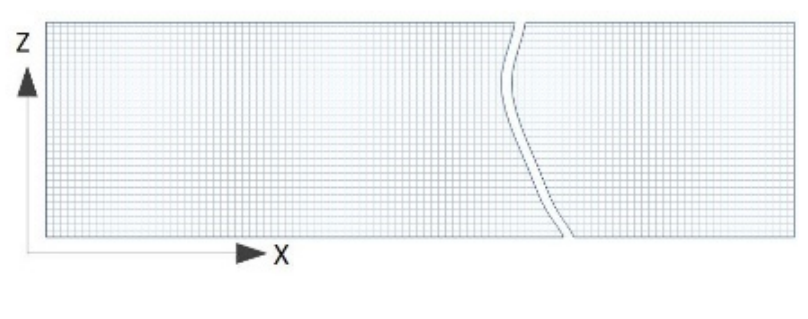

(b) Expanded oil film mesh

Figure 4. Bearing load of a single bearing friction pair and oil film.

The two interacting surfaces of sliding bearing pair are rough in the micro level after machining and the oil film thickness can reach the magnitude of the pair surface roughness under heavy load. In order to consider the influence of rough peaks and valleys on the flow in lubricating film, the Patir and Cheng average Reynolds equation of elastohydrodynamic 
lubrication model considering micro dynamic lubrication effect is adopted, its expression is as follows:

$$
-\frac{\partial}{\partial x}\left(\theta \cdot \alpha_{x}^{2} \cdot \frac{\partial p}{\partial x}\right)-\frac{\partial}{\partial z}\left(\theta \cdot \alpha_{z}^{2} \cdot \frac{\partial p}{\partial z}\right)+\frac{\partial(\theta \cdot \beta)}{\partial x}+\frac{\partial(\theta \cdot \gamma)}{\partial t}=0
$$

In the above expression,

$$
\begin{aligned}
& \alpha_{x}^{2}=\phi_{x} \cdot \frac{h^{3}}{12 \cdot \eta} \\
& \alpha_{z}^{2}=\phi_{z} \cdot \frac{h^{3}}{12 \cdot \eta} \\
& \beta=\left(\gamma+\sigma \cdot \phi_{s}\right) \cdot \frac{u_{1}-u_{2}}{2} \\
& \gamma=\rho \bar{h}_{T}
\end{aligned}
$$

Here $x, z$ are the circumferential and axial coordinates; $p=p(x, z, t), h=h(x, z, t)$ is film pressure and film thickness; $\phi_{x}, \phi_{y}$ is the pressure flow factor along the $x, z$ direction; $\phi_{s}$ is the shear flow factor, used to characterize the effect of rough surface on flow; $\theta=\theta(x, z, t)$ is the filling rate of lubricating oil; $u_{1}$ and $u_{2}$ are the circumferential velocity of shaft and bearing; $t$ is time; $\bar{h}_{T}$ is the mathematical expectation of actual oil film thickness under normal distribution. The oil film pressure at both ends of the bearing is considered equal to the gas pressure of the crankcase and the oil film pressure at the oil hole position is considered equal to the oil supply pressure. The Jakobsson-Floberg-Olsson (JFO) method is used to consider capitation. The boundary condition at the oil film rupture is

$$
\frac{\partial p}{\partial n}=0, p=p_{c}
$$

The boundary condition at the oil film formation is

$$
\frac{h^{2}}{12 \eta} \frac{\partial p}{\partial x}=\frac{V_{n}}{2}(1-\bar{\theta})
$$

The axial boundary condition is

$$
p=p_{e}\left(z= \pm \frac{B}{2}\right)
$$

Periodic boundary condition is

$$
\left.p\right|_{\theta=p}=\left.p\right|_{\theta=2 x}
$$

where $p_{c}$ is the hole pressure; $V_{n}$ is the normal velocity of the interface; $p_{e}$ is environmental pressure.

\section{Oil film thickness relation expression}

In the calculation of actual oil film thickness, the effects of surface roughness, elastic deformation and wear are considered:

$$
h_{T}=h+\delta_{p}+\delta_{T}+\delta
$$

where $h$ is the nominal oil film thickness, which is the distance between the nominal dimensions of two rough surfaces; $\delta_{T}$ is thermal deformation; $\delta$ is the film thickness caused by roughness; $\delta_{p}$ is the elastic deformation of the node on the surface. According to the displacement translation equation and the principle of minimum potential energy in elasticity, the node deformation is established to solve the elastic displacement:

$$
\begin{aligned}
& X+\frac{\partial \sigma_{x}}{\partial x}+\frac{\partial \tau_{x y}}{\partial y}+\frac{\partial \tau_{x z}}{\partial z}=0 \\
& Y+\frac{\partial \tau_{y x}}{\partial x}+\frac{\partial \sigma_{y}}{\partial y}+\frac{\partial \tau_{y z}}{\partial z}=0 \\
& Z+\frac{\partial \tau_{z x}}{\partial x}+\frac{\partial \tau_{x y}}{\partial y}+\frac{\partial \sigma_{z}}{\partial z}=0
\end{aligned}
$$




$$
\{F\}^{q}=\int_{\widetilde{\Omega}}[D]^{T}[E][D] \mathrm{d} \widetilde{\Omega} \cdot\{\lambda\}^{q}
$$

where $F$ is the resultant force vector of the node external force; $\lambda$ is the node displacement array; $E$ is the modulus of elasticity; $D$ is a shape function that can be transformed into nodes; $\widetilde{\Omega}$ is the finite element region.

\section{Viscosity model of lubricating oil}

Because the working condition of internal combustion engine changes frequently, the viscosity of lubricating oil is sensitive to temperature to adapt to different working conditions, such as lubrication and heat dissipation function. The Vogel equation is often used as viscosity temperature equation of lubricating oil [25]. The parameters are shown in Table 5, according to the model:

$$
\mu(T)=A \cdot e^{\frac{B}{T+C}}
$$

Table 5. Basic parameters of SAE 0W20 lubricating oil.

\begin{tabular}{cc}
\hline Density below $40{ }^{\circ} \mathrm{C}$ & $832.5 \mathrm{~kg} / \mathrm{m}^{3}$ \\
Dynamic viscosity below $40{ }^{\circ} \mathrm{C}$ & $37.5 \mathrm{mPa} \mathrm{s}$ \\
Dynamic viscosity below $100^{\circ} \mathrm{C}$ & $6.8 \mathrm{mPa} \mathrm{s}$ \\
$\mathrm{HTHS}$ viscosity at $150{ }^{\circ} \mathrm{C}$ and shear rate of $10^{6}$ & $2.7 \mathrm{mPa} \mathrm{s}$ \\
$1 / \mathrm{s}$ & \\
\hline
\end{tabular}

The pressure in the oil film increases and the intermolecular distance decreases; the intermolecular force of the lubricating oil increases; this leads to the increase of viscosity. In the future, high speed and heavy load development tendency will increases the local oil film pressure to be as high as $200 \mathrm{MPa}$ and the viscosity pressure effect of the lubricating oil will be very significant at the same time. The Barus equation is often used to express the viscosity pressure relationship of lubricating oil:

$$
\eta(T, p)=\eta(T) \cdot e^{\alpha \cdot p}
$$

Under the dynamic load and high running speed, the shear rate in the bearing may exceed $2 \times 10^{7} 1 / \mathrm{s}$. With the increase of the shear rate, the shear thinning effect will occur, resulting in the obvious decrease of the lubricant viscosity. The Cross equation can be used to fit test data:

$$
\eta(T, p, \dot{\gamma})=\eta(T, p) \cdot\left(r+\frac{1-r}{1+(K \cdot \dot{\gamma})^{m}}\right)
$$

For the properties' parameters of standard oil SAE 0W20, refer to the Table 6 below [26], "HTHS" represents high temperature, high sheer rate.

Table 6. Rheological parameters of lubricant.

\begin{tabular}{cc}
\hline Parameters & Value \\
\hline $\mathrm{A}$ & $0.0516 \mathrm{mPa} \mathrm{s}$ \\
$\mathrm{B}$ & $1127.6^{\circ} \mathrm{C}$ \\
$\mathrm{C}$ & $130.7^{\circ} \mathrm{C}$ \\
$\alpha$ & $0.000951 / \mathrm{bar}$ \\
$\gamma$ & 0.53 \\
$\mathrm{~m}$ & 0.79 \\
$\mathrm{~K}$ & $7.9 \times 10^{-8} \mathrm{~s}$ \\
\hline
\end{tabular}

When only viscosity temperature relationship is considered, the comparison of viscosity temperature relationship between SAE 15W40 and SAE 0W20 standard oil depicts in Figure 5, using data from the standard oil database in AVL Excite software. 


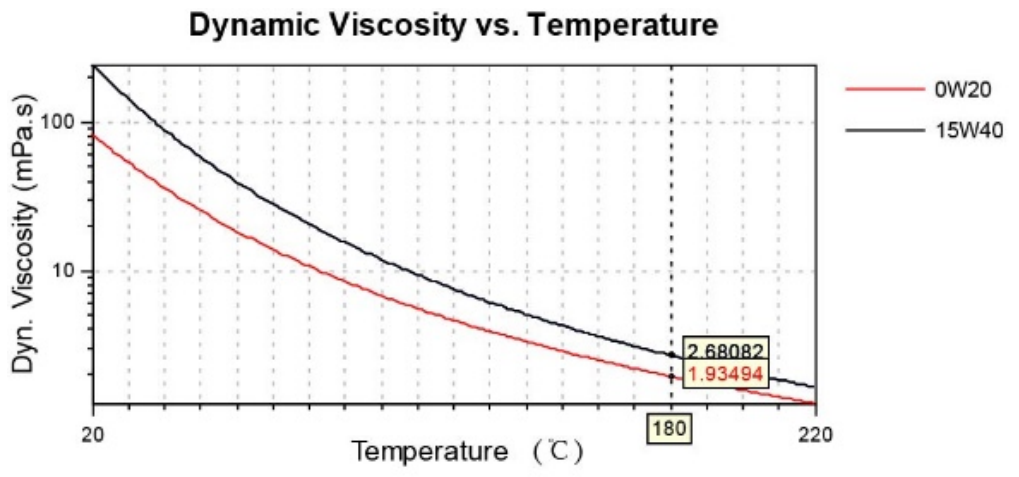

Figure 5. Comparison of viscosity temperature relationship between SAE 15W40 and SAE 0W20 standard oils.

The comparison of viscosity pressure and shear thinning effect of SAE 0W20 standard oil is shown in Figure 6:

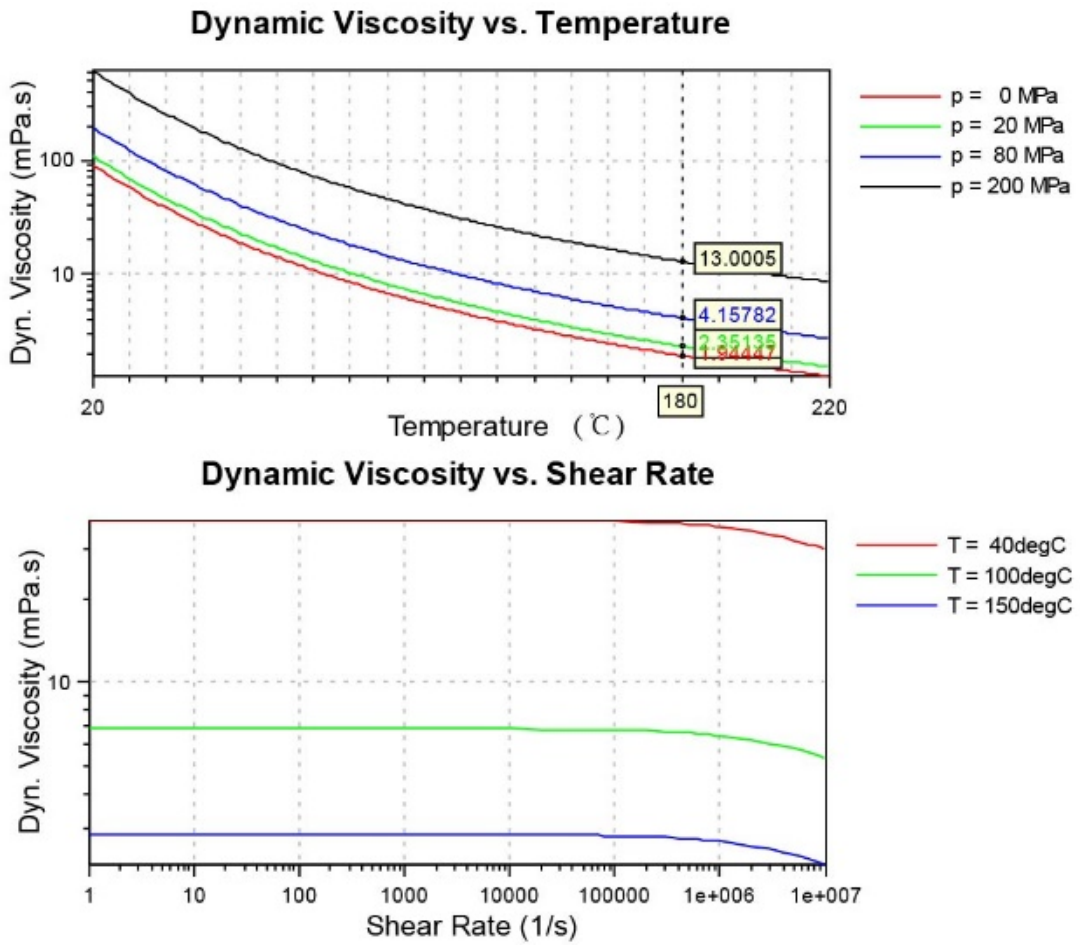

Figure 6. Viscous pressure and shear thinning effect of SAE 0W20 Standard Oil.

The comparison of viscosity temperature relationship between SAE 15W40 and SAE OW20 standard oil depicts in Figure 5, using data from the standard oil database in AVL Excite software.

\section{Rough contact model}

After multiple machining processes, the surface of sliding bearing pair cannot be completely smooth and the dynamic pressure oil film thickness is so small under heavy load conditions and even reaches the order of roughness (several microns), that the rough contact of rough surface cannot be ignored. The contact pressure between rough peaks can be calculated by Greenwood/Tripp model [8]:

$$
P_{a}=\frac{16 \sqrt{2} \pi}{15}\left(\eta_{s} \bar{\beta} \sigma_{s}\right)^{2} \sqrt{\frac{\sigma_{s}}{\beta}} \mathrm{E}^{*} F_{\frac{5}{2}}\left(H_{s}\right)
$$

where 
Deformation function: $F_{\frac{5}{2}}=\left\{\begin{array}{cc}4.40861^{-5}\left(4-\frac{h}{\sigma_{s}}\right)^{6.804} & , \frac{h}{\sigma_{s}}<4 \\ 0, & \frac{h}{\sigma_{s}} \geq 4\end{array}\right.$
Comprehensive elastic modulus: $\mathrm{E}^{*}=\frac{1}{\left(\frac{1-v_{1}^{2}}{\mathrm{E}_{1}}+\frac{1-v_{2}^{2}}{\mathrm{E}_{2}}\right)}$

$\mathrm{E}_{k}(k=1,2), v_{k}(k=1,2)$ and $\eta_{s}$ represents the elastic modulus, Poisson's ratio and the number of roughness peaks in the normal contact area; the number represents the two surfaces of the friction pair; $\bar{\beta}$ is the density of the asperity peak; $\beta$ Curvature radius at the top of asperity. For general engineering surfaces, $\eta_{s} \bar{\beta} \sigma_{s}=0.04, \frac{\sigma_{s}}{\beta}=0.001, \sigma_{s}$ is the comprehensive RMS (Root Mean Square) roughness between two rough surfaces, which can be calculated by the following formula:

$$
\sigma_{s}=\sqrt{\sigma_{1}^{2}+\sigma_{2}^{2}}
$$

The ratio of rough contact area in lubrication area is

$$
R_{\text {contact }}=\frac{\int_{A} d A, \text { where } p_{c}>0}{A_{\text {total }}}
$$

\section{Friction loss in mixed lubrication condition}

The friction loss under mixed lubrication can be obtained by integrating the oil film shear stress and rough peak shear stress along the whole bearing surface [27]:

$$
M_{\text {Friction }}=r \iint_{A}\left(\tau_{h}+\tau_{a}\right) d x d y
$$

According to the shear flow factor and pressure flow factor introduced by Equation (6), the oil film shear stress can be expressed as

$$
\tau_{h}=\eta \frac{u_{1}-u_{2}}{h}\left(\phi_{f} \pm \phi_{f s}\right) \pm\left(\phi_{f p} \frac{h}{2} \frac{\partial p}{\partial x}\right)
$$

where "+" and "-" represent the surface of bearing bush and bearing surface respectively and the contact shear stress of asperity is:

$$
\tau_{a}=\mu_{\text {Bound }} \cdot p_{a}
$$

The friction coefficient of boundary lubrication is selected according to reference [10] $\mu_{\text {Bound }}=0.02$.

\subsection{Physical Models and Calculation Working Condition}

\section{Engine parameters, material properties and boundary conditions}

In the modeling process, the model parameters, material properties and dynamic boundary conditions of the research object are shown in Table 1.

Material parameters of bearing pair can be seen in Table 7. From the free end to the flywheel end, there is No. 1 to No. 7 bearings. To help understand the structure of the research object, the mesh models were established by the Hypermesh software of the engine block, cylinder liners, bearing seats, main bearings and the crankshaft are shown in Figure 7 . 
Table 7. Geometric character and material properties.

\begin{tabular}{ccc}
\hline Term & Crankshaft & Bearing \\
\hline Diameter $(\mathrm{mm})$ & 97 & 97.51 \\
Width $(\mathrm{mm})$ & 33 & 30.3 \\
Elastic modulus $(\mathrm{MPa})$ & 210,000 & 212,000 \\
Poisson's ratio & 0.3 & 0.3 \\
r.m.s Roughness $(\mu \mathrm{m})$ & 0.13 & 0.28 \\
Height of rough peak $(\mu \mathrm{m})$ & 0.21 & 0.39 \\
Bearing clearance $(\mathrm{mm})$ & & \\
\hline
\end{tabular}

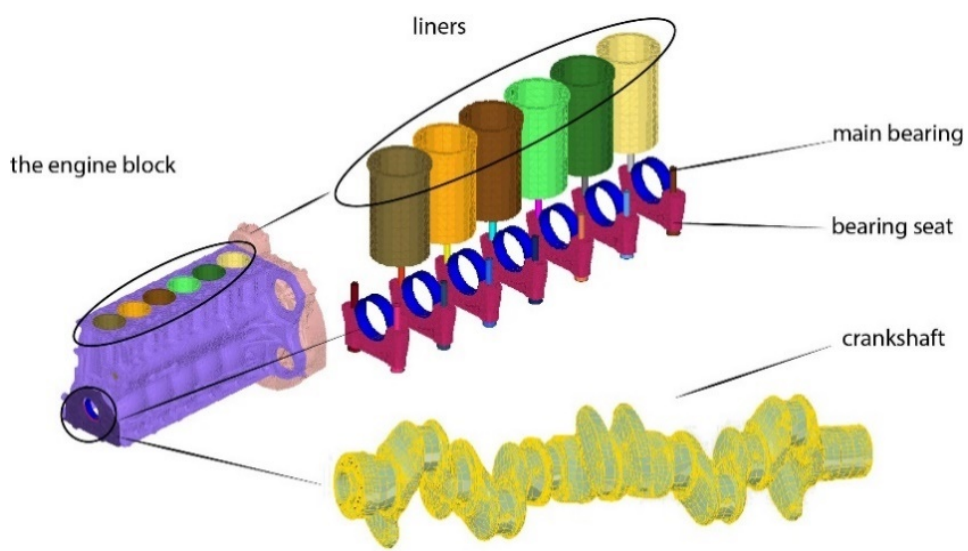

Figure 7. Component mesh model for multi-body dynamics.

\section{Calculation condition, measured loading and oil supply condition}

For the crankshaft bearing nonlinear dynamic model requires high boundary conditions, the dynamic parameters measured by laboratory bench test are mostly used as the boundary conditions under typical working conditions, as shown in Table 8.

Table 8. Working conditions of simulation.

\begin{tabular}{cccc}
\hline NO. & $\begin{array}{c}\text { Speed } \\
(\mathbf{r} / \mathbf{m i n})\end{array}$ & $\begin{array}{c}\text { Explosion Pressure } \\
(\mathbf{M P a})\end{array}$ & $\begin{array}{c}\text { Oil Supply Pressure } \\
(\mathbf{M P a})\end{array}$ \\
\hline 1 & 600 & Engine calibration & 216 \\
2 & 1000 & 25 & 343.5 \\
3 & 1400 & 25 & 412.5 \\
4 & 1900 & 25 & 419 \\
5 & 2150 & Engine calibration & 419 \\
\hline
\end{tabular}

Solving the above equation, the Reynolds equation, energy equation and the heat conduction equation of bearing bush simultaneously, the lubrication between the crankshaft main journal and main bearing experience hydrodynamic lubrication, mixed lubrication and boundary lubrication. According to the ratio of the distance between the nodes of the shaft bearing surface and the comprehensive roughness of the two surfaces $(\mathrm{h} / \sigma)$, the different states of the shaft bearing are distinguished and calculated by the corresponding model. The Reynolds equation is solved by the finite difference method and the elastic displacement equation and the energy equation are solved by the finite element method. The whole calculation process is shown in Figure 8 and the calculation control accuracy of each parameter is shown in Table 9. 


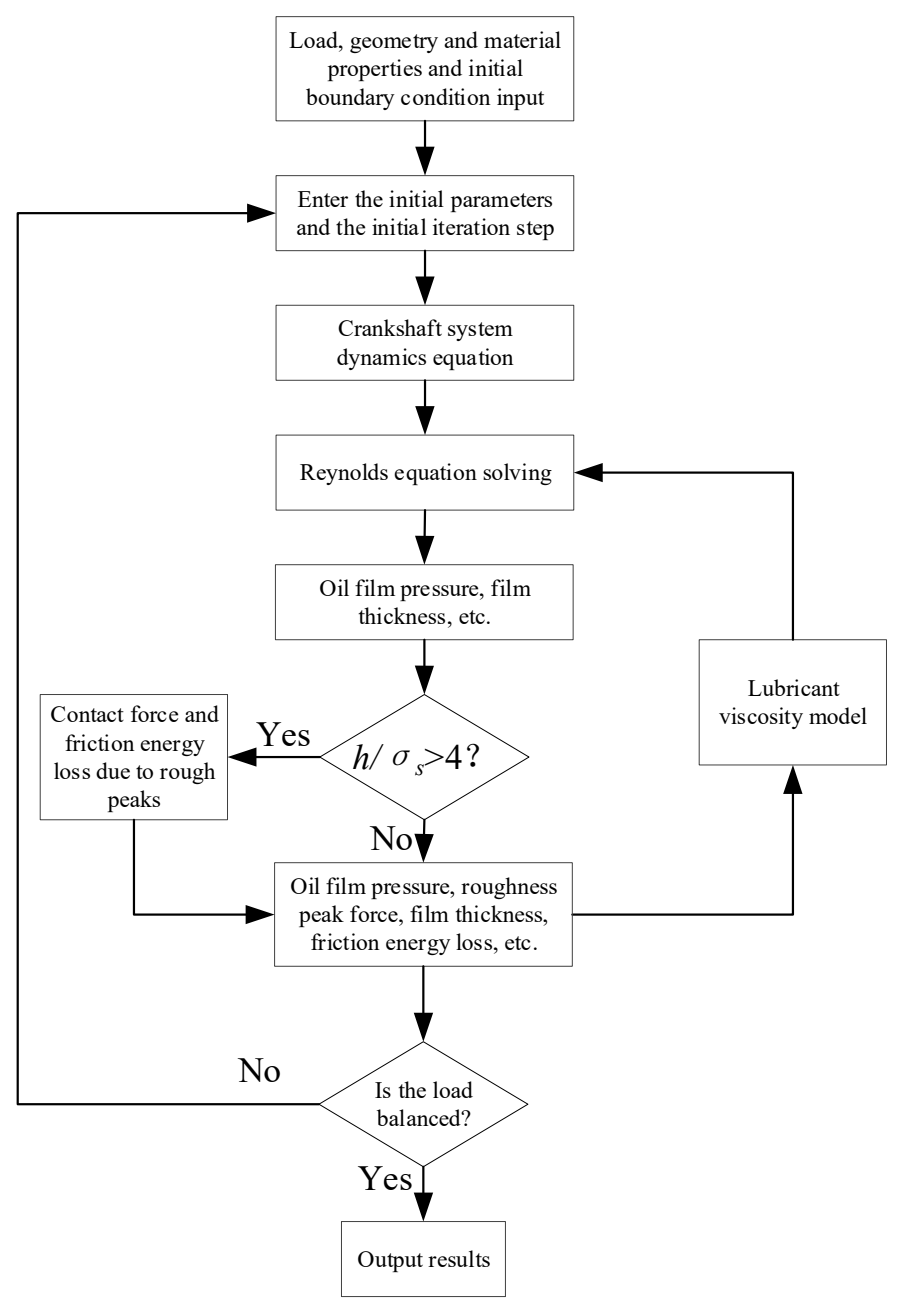

Figure 8. Calculation flow-process diagrams.

Table 9. Control parameters of Solver.

\begin{tabular}{cc}
\hline Parameter & Value \\
\hline Initial step length & $0.0625 \mathrm{deg}$ \\
Minimum step length & $0.001625 \mathrm{deg}$ \\
Maximum step length & $0.125 \mathrm{deg}$ \\
Maximum number of iterations & 2000 \\
Dynamic structural force N & 0.001 \\
Temperature & $0.001 \mathrm{~K}$ \\
Oil film pressure & 0.01 \\
\hline
\end{tabular}

\subsection{Model Accuracies Analyses}

In the lubrication numerical calculation, the number of grids plays an important role in the simulation results. In order to obtain the grid independence results and verify the grid independence, the selected grids are (number of axial grids $\times$ number of circumferential grids) $12 \times 120,18 \times 120,24 \times 120,24 \times 240,48 \times 240$, and $24 \times 480$; the maximum oil film pressure and minimum oil film thickness calculated by each meshing method are shown in Figure 9. 

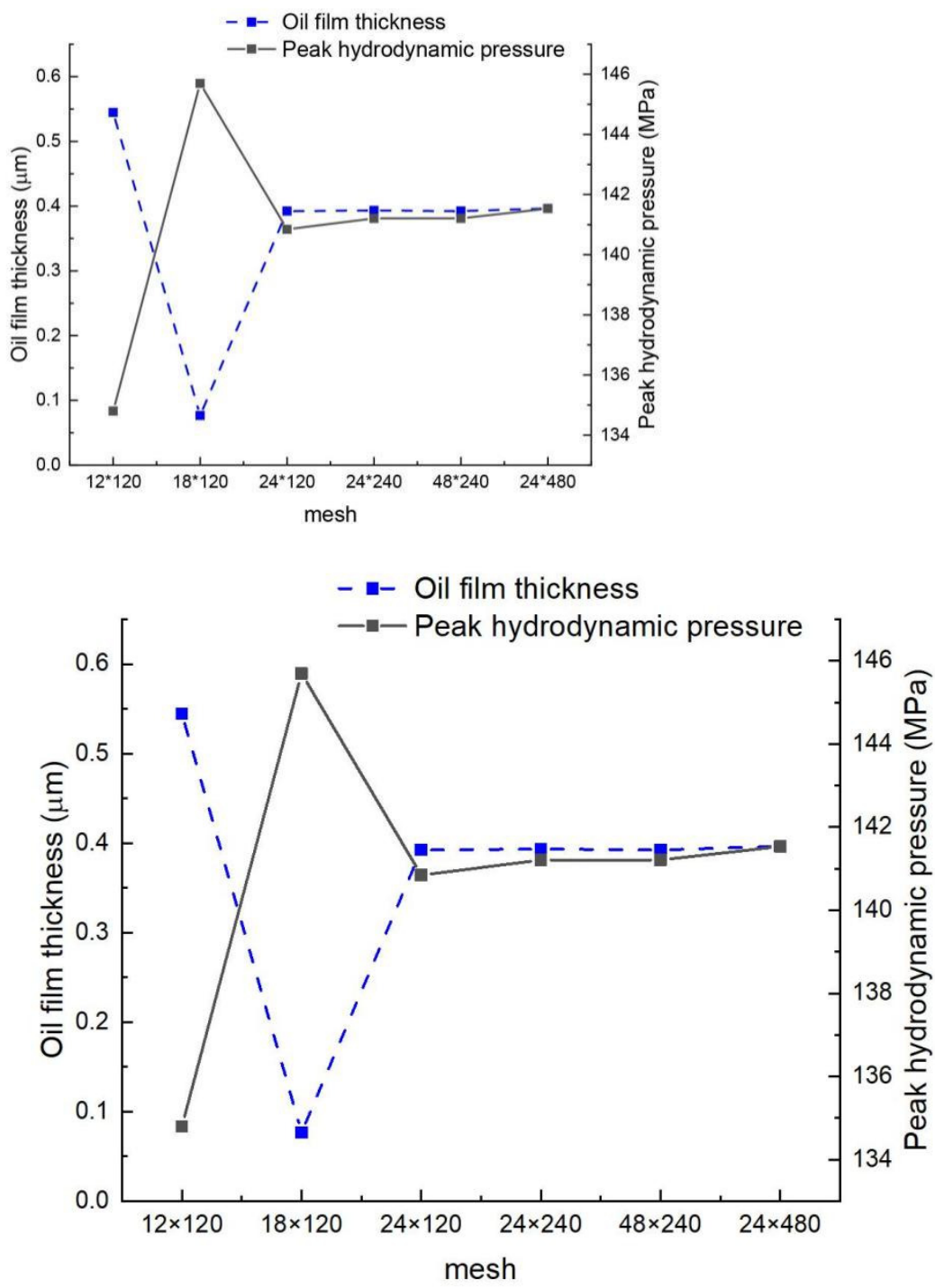

Figure 9. Mesh size independent verification.

It can be seen from the result that with the increase of mesh density, the calculation results tend to be stable and the error is less than $1 \%$ after $24 \times 240$ groups. Considering the calculation accuracy and efficiency, the $24 \times 240$ mesh a method is adopted in the further simulation.

The simulation model of this work is established by coupling the kinetic model of the engine and lubrication model of the lubrication oil film. The accuracy of the whole model is dependent on the accuracy of each model. For the engine kinetic model, the calculated results are strongly influenced by the dynamic boundary conditions, such as the rotating speed and cylinder pressure, so the measured data for the boundary conditions from a real engine bench test under typical working conditions is used. In the experiment, the speed signal of the crankshaft is measured and controlled by the closed-loop method by the dynamometer with an accuracy of $\leq \pm 1 \mathrm{r} / \mathrm{min}$ as shown in Table 2; the dynamic load transmitted from the combustion cylinder to the main bearing calculated by the kinetic simulation model is verified by the bearing interaction force obtained by the quasi-static simple beam theory of structural mechanics, the comparison of the two curves in Figure 10 shows that the dynamic load curve and the theoretical results have similar trends, except that the dynamic simulation results fluctuate slightly due to explosive pressures from other cylinders of this multi-cylinder engine. The reliability of the simulation results is obtained from the consistency of the two curves above. 


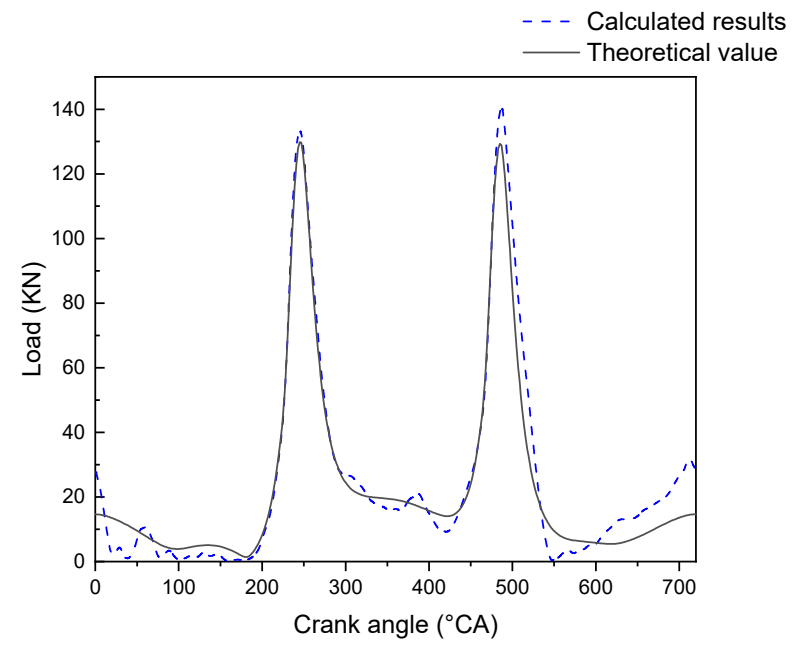

Figure 10. Theoretical and simulation comparison curves.

For the fluid lubrication model, the generalized Reynolds equation is adopted, the applicability of which has been confirmed by many scholars, but the accuracy of the method is strongly related to the mesh size of the oil film, so we conducted the grid independence analysis for several mesh patterns, as shown in Figure 9. Furthermore, the load boundary condition of the Reynolds equation uses the force of the bearing joint obtained by the above kinetic model as the input force boundary condition for the oil film solution, the initial pressure of the solution is obtained from the measured oil supply pressure in the bench test to ensure the validity of the entire coupled simulation model.

\section{Results and Discussion}

This section contains simulation results analysis of the crankshaft bearings and economic analysis of profit gained by using low viscosity oil.

\subsection{Simulation Data Analysis}

As shown in Figure 11, the hydraulic friction loss of lower viscosity oil is lower than that of normal viscosity oil in each typical working condition and the decreasing amplitude at $2150 \mathrm{rpm}$ is more obvious with the increase of rotating speed, which reach up to $24 \%$ : nearly a quarter. While the low viscosity oil is applied, the bearing capacity of oil film drops, the asperity friction power loss of typical working conditions is multiplied several times, even dozens of times high as when using normal viscosity oil, which may lead to the decrease of hydrodynamic friction power loss by using low viscosity oil is partly or even fully neutralized by asperity friction power loss and the rough contact between two surfaces can also lead to bearing wear, which not only changes the lubrication and friction characteristics, but also causes severe failure of other components.

To link the typical working conditions of this engine to the endurance cycle, here reports an example of a statistical average benefit of the engine during service. The reduction in hydraulic friction loss at the lower viscosity oil was as much as $24 \%$ at $2150 \mathrm{rpm}$ (maximum idle speed) operating conditions, but the benefits are less under other operating conditions. In order to assess the friction reduction effect in a more practical way, the average friction reduction effect is assessed using the endurance cycle. The endurance cycle load spectrum is based on the company's internal design criteria and experience with this model, which involves a statistical value for the percentage of operating time for each typical operating condition and can be used as an equivalent to the actual service process. The friction reduction effect and time share of each typical operating condition in one cycle are shown in the Table 10 below. 


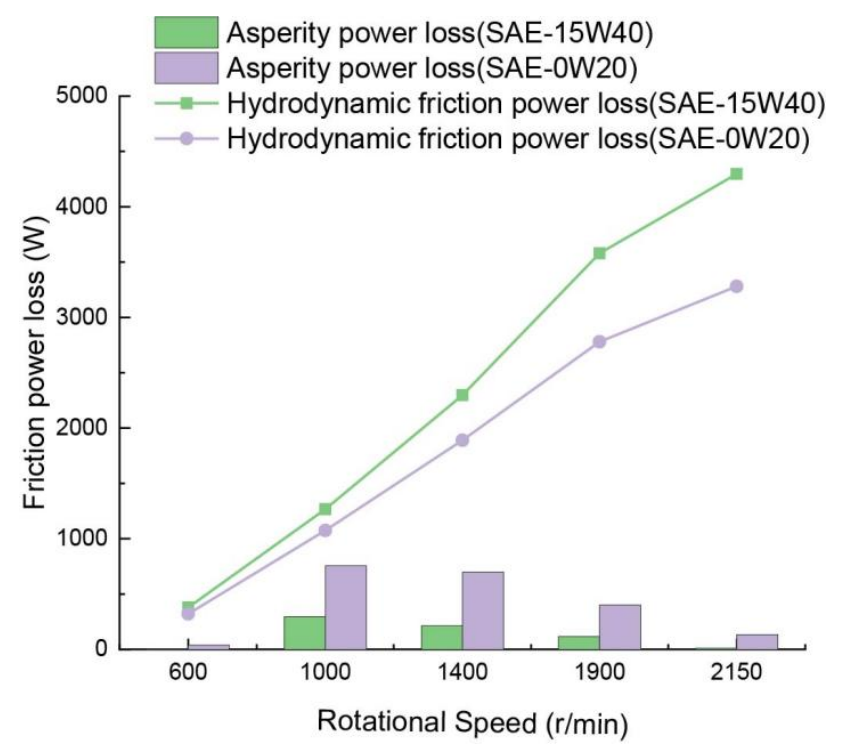

Figure 11. Comparison of total friction power consumption of main bearing with normal viscosity oil and low viscosity oil under typical working conditions.

Table 10. The endurance cycle and friction benefits.

\begin{tabular}{ccc}
\hline Working Condition/rpm & Hydraulic Friction Reduced & Time Share \\
\hline 600 & $15.30 \%$ & $1.69 \%$ \\
1000 & $15.25 \%$ & $11.14 \%$ \\
1400 & $17.71 \%$ & $34.38 \%$ \\
1900 & $22.32 \%$ & $38.74 \%$ \\
2150 & $23.63 \%$ & $14.04 \%$ \\
\hline
\end{tabular}

The increase in friction loss due to rough peak friction under the endurance cycle is hydraulic friction reduced multiplied by the corresponding time share under each working condition. To conclude the example, the overall hydrodynamic friction reduction effect of the internal combustion engine according to its endurance cycle is about $20 \%$. Other standard cycles can be applied to assess the applicable benefits given the corresponding tested boundary conditions.

The minimum oil film thickness is the key parameter to characterize the lubrication performance. Figure $12 \mathrm{a}-\mathrm{c}$ show the variation of the minimum oil film thickness in a period with rotating speed in each cycle of the main bearing when using the lubricant with different viscosity. After comprehensively comparing the minimum oil film thickness in a period of each main bearing under typical conditions when, respectively, using SAE 15W40 $\eta(t)$, SAE 0W20 $\eta(t)$ and SAE 0W20 $\eta(t, p, \dot{\gamma})$, it can be seen that whether considering the pressure-viscosity and shear thinning effects or not, the use of lower viscosity oils (SAE 0W20) causes obvious decrease of minimum oil film thickness in a period under typical working conditions with respect to when using normal viscosity oil (SAE 15W40). When SAE 0W20 oil is used, two conditions of whether the pressure-viscosity and shear thinning effects are included in the viscosity model or not are compared. In addition, it can be concluded that, for the same kind of lubricant, the pressure-viscosity effect caused by the local increase of oil film pressure induces the increase of both the oil viscosity and bearing capacity of the main bearing. The shear thinning effect caused by local strong shear reduces the oil viscosity and the bearing capacity of the main bearing. After applying the new viscosity model which has considered the two effects above, the minimum oil film thickness in a period of main bearing shows a slight increasing trend on the whole, which explains that the bearing capacity of a main bearing is promoted after adopting the new 
model. It follows that the increase of oil viscosity caused by the pressure-viscosity effect after using low viscosity oil plays a more important role than that of shear thinning effects.
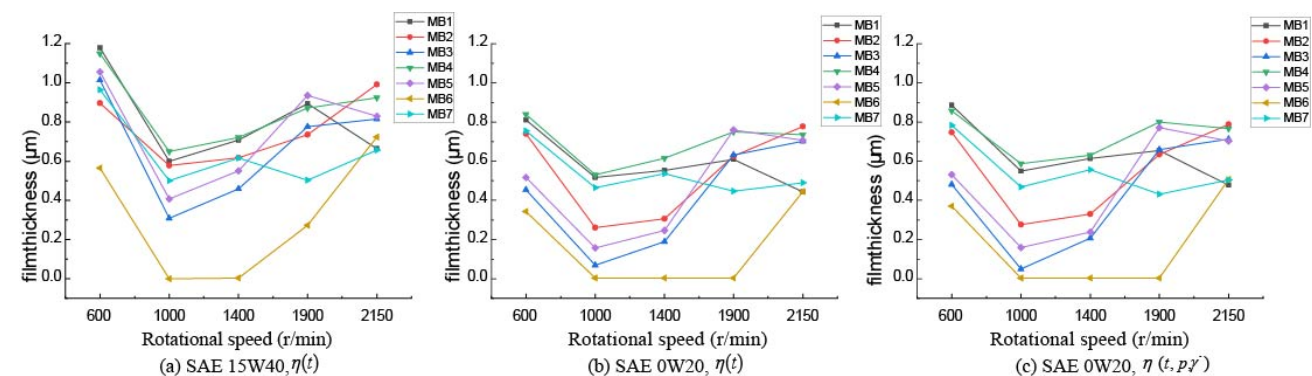

Figure 12. Minimum oil film thickness of each main bearing under typical working conditions.

There are seven main bearings in a 6-cylinder engine, interacting with seven main shaft segments in the same crankshaft. MB1 refers to No.1 main bearing and MB2 refers to No.2 main bearing and so on. To simplify the expression, the name of each main bearing in the

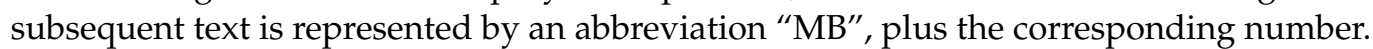

According to the oil film thickness, it can be seen that the main bearings remain in the mixed lubrication state under the rated speed and rated high torque conditions. The asperity contact area ratio between the two surfaces of the friction pair of main bearing under each typical working condition is extracted, as shown in Figure 12.

Figure 13a-c, respectively, show the variation of asperity contact percentage in a period of main bearing with rotating speed when adopting different viscosity. After comprehensively comparing the asperity contact percentage in a period of each main bearing under typical conditions when, respectively, using SAE 15W40 $\eta(t)$, SAE 0W20 $\eta(t)$ and SAE 0W20 $\eta(t, p, \dot{\gamma})$, it can be seen that whether or not considering the oil stick after pressure effect and shear thinned effect, after using lower viscosity oil (SAE 0W20), the asperity contact percentage of main bearing under different typical working conditions significantly increase compared to when using normal viscosity oil (SAE 15W40); among them, the asperity contact percentage of $3 \#$ and $5 \#$ main bearings under typical conditions increases to more than four times. When the SAE 0W20 oil is used, two conditions of whether the pressure-viscosity and shear thinning effects are included in the viscosity model or not are compared. In addition, it can be concluded that, for the same kind of lubricant, the pressure-viscosity effect caused by the local increase of oil film pressure induces the increase of both the oil viscosity and bearing capacity of the main bearing. The shear thinning effect caused by local strong shear reduces the oil viscosity and the bearing capacity of the main bearing. After applying the new viscosity model which has considered the two effects above, the asperity contact percentage in a period of main bearing shows a slight decreasing trend on the whole, which explains that the bearing capacity of main bearing is promoted after adopting the new model. It follows that the increase of oil viscosity caused by the pressure-viscosity effect after using low viscosity oil plays a more important role than that of shear thinning effects, which are consistent with the influence law of minimum oil film thickness in a period. 


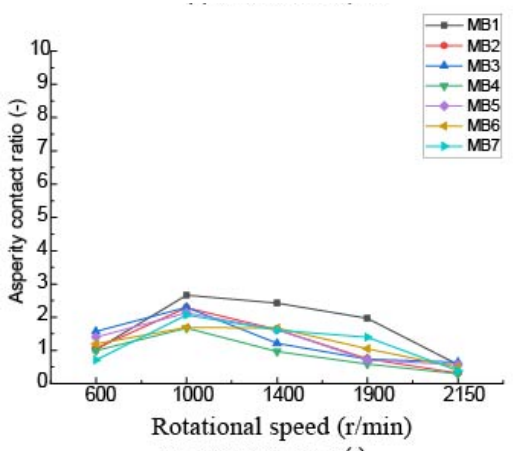

(a) SAE $15 \mathrm{~W} 40, \eta(t)$

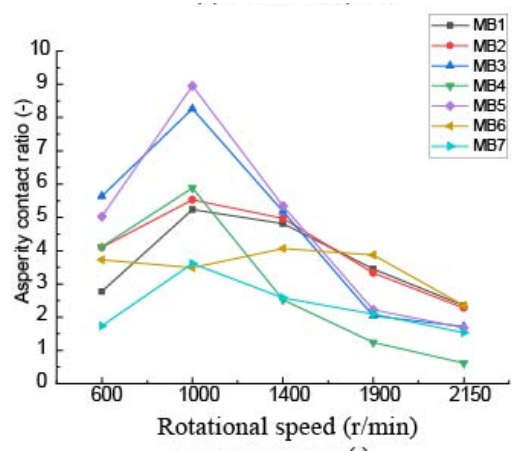

(b) SAE 0W20, $\eta(t)$

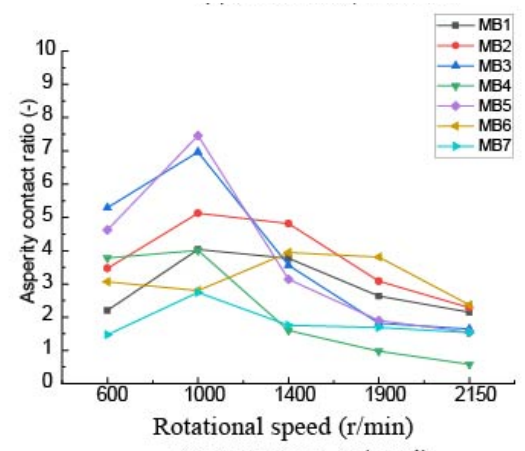

(c) SAE 0W20, $\eta\left(t, p \gamma^{\prime}\right)$

Figure 13. Asperity contact ratio of main bearings under typical working conditions.

To simplify the expression, the name of each main bearing in the subsequent text is represented by an abbreviation "MB" plus the corresponding bearing number, too.

For the six-cylinder engine, No. 6 main bearing (MB6) suffered the worst lubrication condition. Different from the other main bearings, the minimum film thickness drops to near zero, which means asperity contact occurs between the bearing and journal surface. To analyze the reason behind this phenomenon, load characters of the difference for different cylinders. The peak explosive pressure value in each cylinder is almost the same, with a phase difference of $120^{\circ} \mathrm{CA}$ (Crank angle). The 7 main bearings supporting the same crankshaft system. With a pulley at the front end of the crankshaft and a flywheel at the rear end, the torque output of a multi-cylinder internal combustion engine transmits the torque and accumulates from the front end of the crankshaft to the rear end. Moreover, two thrust bearings are mounted on both sides of the MB6 to limit the axial displacement of the crankshaft. These are likely to result in a greater load on the main bearing No. 6 compared to other bearings and resulting in a relatively lower load carrying capacity for the same oil supply conditions; thus, its cyclic minimum oil film thickness is less than other bearings in all typical operating conditions.

To synthesize the specific performance of the low viscosity oil and the mechanism, load capacity parameters, oil film thickness and the asperity contact ratio under typical working conditions were investigated, the pressure-viscosity relation is dominant when low viscosity oil is adopted. A drop in the cyclic minimum film thickness and an increase in the asperity contact ratio indicates that lower viscosity in engine bearing may induce lubrication deterioration and increase friction caused by rough peaks of the joint surfaces.

\subsection{Economic Analysis}

To estimate the economic gain by using ultra low viscosity oil in ICEs, for example, regarding the SAE 0W20 oil, up to $24 \%$ of frictional energy consumption will be saved. At present, there are about 1040 million road vehicles in the transportation sector; the energy used in road cars is 83 EJ annually [6] and, of that total, about 3-4\% used to overcome engine bearing friction; about $0.96 \%$ of the total energy will be saved, which is 0.8 EJ annually.

The economic impact of friction energy loss and wear related issue can be estimated based on the energy cost of overcoming friction, the cost of the energy required to manufacture wear-related replacement parts and spare equipment and the cost of maintenance and repair work. The global average price of 1 GJ of energy is 18 EUR used [28], for all the road vehicle the amount of 14,343 million EUR cost will be saved by using SAE OW20 oil. The energy consumption of $1 \mathrm{PJ}$ results in $0.0683 \mathrm{MtCO}_{2}$ carbon dioxide emissions on average global level according to research [6]; by reducing the $0.8 \mathrm{EJ}$ friction energy consumption, the $\mathrm{CO}_{2}$ emissions can be cut down by $54.6 \mathrm{Mt}$, which means that up to $3.7 \%$ of the estimated carbon dioxide emission in the next 8 years-according to Holmberg's investigation of $1460 \mathrm{MtCO}_{2}$ of emissions—can be reduced globally [6]. There are additional potential energy savings if new anti-wear material and coating techniques are applied to 
the surface of the friction pairs to reduce the friction loss caused by asperity friction due to low viscosity lubricants in the future.

\section{Conclusions}

In this paper, the working and lubricating properties of the main bearings of ICE with demands of the application of low viscosity oil are analyzed, the economical profits of using low viscosity to improve the efficiency of road cars were estimated as well. The results show that the application of low viscosity oil makes the hydrodynamic friction power loss decrease up to $24 \%$, but the increase of friction loss caused by the aggravation of asperity contact between surfaces may counteract the reducing effect of hydrodynamic friction power loss and the aggravation of asperity contact may also lead to bearing wear.

For the economic profit, the application of low viscosity oil in future high efficiency engine can bring about a saving of up to 14,343 million EUR, cutting down $3.7 \%$ of the estimated carbon dioxide emission in the next 15 years. In this study, the method of main bearing lubrication simulation based on low viscosity oil can provide support for the study of the application of low viscosity oil in the internal combustion engine to improve efficiency and can provide references for the technology policy development.

In this paper, we consider rough surface and the flexibility of the crankshaft and the main bearings for low viscosity oil. In the future, we will include the cavitation in the model and analyze all these factors' effects on friction consumption gain, such as oil leakage. More specifically, we will also establish a test rig to verify the simulation results.

Author Contributions: Conceptualization, Y.Z. and Y.F.; methodology, Y.Z.; formal analysis, Y.Z.; resources, Z.L.; writing - original draft preparation, Y.Z. and Z.M.; writing-review and editing, Z.M., Y.F., Z.D. and Z.L.; supervision, Z.L.; project administration, Z.L. All authors have read and agreed to the published version of the manuscript.

Funding: This research was funded by the project "Research on Dynamic Wear Mechanism and Law of Internal Combustion Engine Main Bearings", supported by Science Fund of State Key Laboratory of Engine Reliability of China (skler-201807).

Institutional Review Board Statement: Not applicable.

Informed Consent Statement: Not applicable.

Data Availability Statement: All the data of the reported results can be found in the paper text.

Conflicts of Interest: The authors declare no conflict of interest.

\section{References}

1. Liu, J.; Dumitrescu, C.E. Methodology to separate the two burn stages of natural-gas lean premixed-combustion inside a diesel geometry. Energy Convers. Manag. 2019, 195, 21-31. [CrossRef]

2. Liu, J.; Dumitrescu, C.E. Combustion partitioning inside a natural gas spark ignition engine with a bowl-in-piston geometry. Energy Convers. Manag. 2019, 183, 73-83. [CrossRef]

3. Liu, J.; Dumitrescu, C.E. Single and double Wiebe function combustion model for a heavy-duty diesel engine retrofitted to natural-gas spark-ignition. Appl. Energy 2019, 248, 95-103. [CrossRef]

4. Liu, J.; Dumitrescu, C.E. Analysis of two-stage natural-gas lean combustion inside a diesel geometry. Appl. Therm. Eng. 2019, 160, 114116. [CrossRef]

5. Liu, J.; Dumitrescu, C.E. Flame development analysis in a diesel optical engine converted to spark ignition natural gas operation. Appl. Energy 2018, 230, 1205-1217. [CrossRef]

6. Holmberg, K.; Erdemir, A. Influence of tribology on global energy consumption, costs and emissions. Friction 2017, 5, 263-284. [CrossRef]

7. Song, H.; Quinton, K.S.; Peng, Z.; Zhao, H.; Ladommatos, N. Effects of Oxygen Content of Fuels on Combustion and Emissions of Diesel Engines. Energies 2016, 19, 28. [CrossRef]

8. Monsalve-Serrano, J.; Belgiorno, G.; Di Blasio, G.; Guzmán-Mendoza, M. 1D Simulation and Experimental Analysis on the Effects of the Injection Parameters in Methane-Diesel Dual-Fuel Combustion. Energies 2020, 13, 3734. [CrossRef]

9. Jamrozik, A.; Tutak, W.; Grab-Rogaliński, K. An experimental study on the performance and emission of the diesel/CNG dual-fuel combustion mode in a stationary CI engine. Energies 2019, 12, 3857. [CrossRef] 
10. Blasio, G.D.; Vassallo, A.; Pesce, F.C.; Beatrice, C.; Avolio, G. The Key Role of Advanced, Flexible Fuel Injection Systems to Match the Future $\mathrm{CO}_{2}$ Targets in an Ultra-Light Mid-Size Diesel Engine. SAE Int. J. Engines 2019, 12. [CrossRef]

11. Liu, J.; Dumitrescu, C.E. Numerical investigation of methane number and Wobbe index effects in lean-burn natural gas sparkignition combustion. Energy Fuels 2019, 33, 4564-4574. [CrossRef]

12. Liu, J.; Dumitrescu, C.E. 3D CFD simulation of a CI engine converted to SI natural gas operation using the G-equation. Fuel 2018, 232, 833-844. [CrossRef]

13. Okuyama, Y.; Shimokoji, D.; Sakurai, T.; Maruyama, M. Study of Low-Viscosity Engine Oil on Fuel Economy and Engine Reliability. No.2011-01-1427. SAE Technical Paper. 2011. Available online: https://saemobilus.sae.org/content/2011-01-1247/ (accessed on 15 March 2021).

14. Holmberg, K.; Andersson, P.; Nylund, N.-O.; Mäkelä, K.; Erdemir, A. Global energy consumption due to friction in trucks and buses. Tribol. Int. 2014, 78, 94-114. [CrossRef]

15. Santos, N.D.S.A.; Roso, V.R.; Faria, M.T.C. Review of engine journal bearing tribology in start-stop applications. Eng. Fail. Anal. 2020, 108, 104344. [CrossRef]

16. Covitch, M.J.; Brown, M.; May, C.; Selby, T.; Goldmints, I.; George, D. Extending SAE J300 to Viscosity Grades below SAE 20. SAE Int. J. Fuels Lubr. 2010, 3, 1030-1040. [CrossRef]

17. Sander, D.E.; Allmaier, H.; Priebsch, H.-H. Friction and Wear in Automotive Journal Bearings Operating in Today's Severe Conditions; IntechOpen: Rijeke, Croatia, 2016.

18. Lugt, P.M.; Morales-Espejel, G.E. A Review of Elasto-Hydrodynamic Lubrication Theory. Tribol. Trans. 2011, 54, 470-496. [CrossRef]

19. Barus, C. ART. X.-Isothermals, Isopiestics and Isometrics relative to Viscosity. Am. J. Sci. 1893, 45, 87. [CrossRef]

20. Sander, D.E.; Allmaier, H.; Priebsch, H.H.; Reich, F.M.; Witt, M.; Füllenbach, T.; Skiadas, A.; Brouwer, L.; Schwarze, H. Impact of high pressure and shear thinning on journal bearing friction. Tribol. Int. 2015, 81, 29-37. [CrossRef]

21. Laouadi, B.; Lahmar, M.; Bou-saïd, B.; Boucherit, H.; Mouassa, A. Analysis of couple-stresses and piezo-viscous effects in a layered connecting-rod bearing. Mech. Ind. 2018, 19, 607. [CrossRef]

22. Anuradha, P. Thermal EHL Analysis of Rolling/Sliding Line Contacts with Shear-Thinning and Interfacial Wall Slip Effects, National Institute of Technology. 2012. Available online: http://idr.nitkkr.ac.in:8080/xmlui/handle/123456789/3440 (accessed on 15 March 2021).

23. Gu, C.; Meng, X.; Zhang, D.; Xie, Y. Transient analysis of the textured journal bearing operating with the piezoviscous and shear-thinning fluids. J. Tribol. 2017, 139, 5. [CrossRef]

24. Katafuchi, T.; Kasai, M. Effect of base stocks on the automobile engine bearing. Tribol. Int. 2009, 42, 548-553. [CrossRef]

25. Vogel, $\mathrm{H}$. The law of the relation between the viscosity of liquids and the temperature. Phys. Z 1921, 22, 645-646.

26. Sander, D.E.; Allmaier, H. Starting and stopping behavior of worn journal bearings. Tribol. Int. 2018, 127, 478-488. [CrossRef]

27. Offner, G.; Knaus, O. A generic friction model for radial slider bearing simulation considering elastic and plastic deformation. Lubricants 2015, 3, 522-538. [CrossRef]

28. Holmberg, K.; Kivikytö-Reponen, P.; Härkisaari, P.; Valtonen, K.; Erdemir, A. Global energy consumption due to friction and wear in the mining industry. Tribol. Int. 2017, 115, 116-139. [CrossRef] 